\title{
COMUNICACIÓN
}

\section{Strongyloidosis no autóctona en Chile. Descripción de un brote familiar}

\author{
LEA SANDOVAL*, RUBEN MERCADO*, WERNER APT*, CARMEN NAVARRETE**, \\ JUAN CONTRERAS-LEVICOY***, MARLENE T. UETA****, \\ MARIA ISABEL JERCIC***** y DOUGLAS CASTILLO*.
}

\section{NON AUTOCHTHONOUS STRONGYLOIDOSIS IN CHILE. REPORT OF A FAMILIAR OUTBRAKE}

\begin{abstract}
A familiar outbrake of strongyloidosis affected peruvian immigrants who had arrived Chile in november 2001 is reported. In march 2002, Strongyloides stercoralis infection of the index individual was confirmed by the Basic-Clinical Laboratory of Parasitology of the Faculty of Medicine of the University of Chile, in Santiago, Chile. At the Roberto del Rio Pediatric Hospital, a 11 years old girl presenting juvenil rheumatoid arthritis and mild abdominal distress was studied. A serial of three stool samples was collected and procesed by ether-centrifugal concentration technique. A plentiful quantity of rhabditoid larvae of $\mathbf{S}$. stercoralis was observed. To detect larvae in the faeces and specific serum antibodies against S. stercoralis by means of ELISA her parents and sister were studied. The mother of the index case and her sister were positive in both test. The father was not infected. The three positive cases were treated with Ivermectine. A control study performed one year later demonstrated a positive ELISA test only in the sister.
\end{abstract}

Key words: Strongyloides stercoralis, Strongyloidosis, Intestinal helminth, Enteroparasite.

\section{INTRODUCCIÓN}

La strongyloidosis es causada por un nematodo de aspecto filiforme, de unos $2 \mathrm{~mm}$ de largo por $50 \mu$ de diámetro. En su fase parasitaria vive en la mucosa del intestino delgado del hombre (duodeno-yeyuno). Este helminto tiene la característica biológica de compartir una fase de vida libre y una parasitaria, que lo hace diferente de otros geohelmintos frecuentes en Chile tales como Áscaris lumbricoides, Trichuris trichiura y Toxocara sp. La mayoría de las infecciones por $S$. stercoralis en individuos inmunocompetentes son crónicas y asintomáticas. En inmunocomprometidos puede observarse un cuadro diseminado grave, a veces de curso fatal. La strongyloidosis es una parasitosis cosmopolita presente en países de clima tropical o templado especialmente de Asia, África y Latinoamérica. En Latinoamérica, es frecuentemente observada en Brasil y Perú donde en algunas localidades cerca del $60 \%$ de la población puede estar

\footnotetext{
* Laboratorio de Parasitología Básico-Clínico. ICBM. Facultad de Medicina. Universidad de Chile.

** Pediatría. Hospital Roberto del Río.

*** Interno de Medicina. Facultad de Medicina Universidad de Chile.

**** Departamento de Parasitología. IB. UNICAMP. Campinas. Sao Paulo. Brasil.

***** Laboratorio de Referencia de Parasitología. Instituto de Salud Pública de Chile.
} 
infectada ${ }^{1}$. En Chile, su epidemiología se encuentra en estudio describiéndose casos aislados y brotes institucionales en internos de hospitales psiquiátricos. En la presente comunicación damos a conocer otra forma posible de presentación de la strongyloidosis en Chile, como es un brote familiar de inmigrantes de países vecinos.

\section{CASO CLÍNICO}

AHR, de 11 años, sexo femenino, de nacionalidad peruana, había llegado a Chile en noviembre del año 2001. Ese mismo año se le había diagnosticado artritis reumatoide juvenil (ARJ) en su país. Su familia se compone de ambos padres y una hermana.

Desde su llegada a Chile comienza a ser controlada en el Hospital Roberto del Río en Santiago, por su ARJ. Al ingreso destacaba gran compromiso funcional en sus extremidades e intenso dolor a la movilización de éstas.

En sus exámenes de ingreso llamaba la atención una acentuada eosinofília de $20 \%$, con un recuento absoluto de 1.560 eosinófilos $/ \mathrm{mm}^{3}$. Además en el examen parasitológico seriado de deposiciones (EPSD) se encontraron quistes de Giardia intestinalis. Se inició tratamiento con metronidazol, metrotexato y ácido fólico, solicitándose exámenes de control de hemograma y EPSD que muestran un recuento de eosinófilos de $1.280 / \mathrm{mm}^{3}$, correspondientes al $10 \%$ del total de leucocitos, y larvas de $S$, stercoralis en la heces. Antes de iniciar el tratamiento antiparasitario se decide estudiar el grupo familiar mediante EPSD de tres muestras fecales y Enzimelinked immunosorbent assay (ELISA) para detectar anticuerpos séricos específicos contra S. stercoralis. Se detecto la infección en otros dos miembros del grupo familiar, la madre y la hermana. Se decide iniciar tratamiento con ivermectina 200 microgramos $/ \mathrm{Kg}$ de peso. Luego de un año se procedió a controlar el resultado del tratamiento antiparasitario con los mismos exámenes. La madre y el caso índice negativizaron ambos exámenes, pero la hermana presentó una ELISA positiva. El padre permaneció negativo (Tabla 1).

\section{DISCUSIÓN Y CONCLUSIONES}

El principal rreservorio de la strongyloidosis
Tabla 1. EPSD y serología de los miembros de la familia infectada con $S$. stercoralis al momento del diagnóstico y un año después del tratamiento antiparasitario con ivermectina

\begin{tabular}{lcccc}
\hline Familia & EPSD & $\begin{array}{c}\text { EPSD } \\
\text { al año }\end{array}$ & $\begin{array}{c}\text { ELISA } \\
\text { IgG }\end{array}$ & $\begin{array}{c}\text { ELISA } \\
\text { IgG } \\
\text { al año }\end{array}$ \\
\hline Madre & + & - & + & - \\
Padre & - & - & - & - \\
Índice & + & - & + & - \\
Hermana & + & - & + & + \\
\hline
\end{tabular}

en una determinada región biogeográfica es el hombre. La infección se adquiere por la penetración de la piel por parte de la larva filariforme la cual por vía linfática o hematógena llega al pulmón, desde donde se desplaza a las vías respiratorias para luego ser deglutida y alcanzar el habitat que es el intestino delgado ${ }^{2}$.

La infección es generalmente asintomática $u$ oligosintomática donde el paciente puede presentar dolor abdominal, diarrea, síntomas respiratorios leves o severos (Síndrome de Löeffler), rash urticarial, acompañado generalmente de eosinofília sanguínea moderada $a^{2,4}$.

En inmunocomprometidos el cuadro puede presentarse como un síndrome de hiperinfección, lo cual puede llevar al paciente incluso a la muerte ya que existe una diseminación general de la parasitosis ${ }^{4}$.

La infección se perpetúa por décadas a través de un ciclo de autoinfección endógena y exógena ${ }^{2}$.

Los métodos existentes para su diagnóstico son: observación microscoscopica, generalmente de las larvas rabditoides directamente en heces o por intermedio del métodos de cultivo como los de Baermann, Rugai o Harada-Mori. ELISA IgG es la técnica indirecta más utilizada en la detección de anticuerpos séricos específicos ${ }^{1,2}$.

El diagnóstico de esta parasitosis es difícil debido a que son escasas las larvas presentes en las heces ya que su eliminación es cíclica ${ }^{3}$.

En Chile, la strongyloidosis es una infección poco estudiada. Existen casos publicados que corresponden a una infección mortal en un paciente que estuvo internado en el Hospital Psiquiatrico de Putaendo ${ }^{4}$; en este mismo recinto en 1985 se encontró $11,6 \%$ de strongyloidosis mediante estudio de muestras fecales de los 
internos $^{5}$. En el 2001 en el Hospital Psiquátrico el Peral de Santiago se pesquisa esta infección en 4 de 20 internos ${ }^{6}$ y en un Centro de Recuperación Nutricional de niños en Arica se detectó en un $16 \%$ de los residentes ${ }^{1}$.

Hay que destacar en el brote familiar de inmigrantes presentado el hecho de que larvas de $S$. stercoralis no fueron detectadas en el primer EPSD del caso índice, ni tampoco en el segundo EPSD de control en la hermana del caso índice lo cual sugiere la baja sensibilidad de los métodos directos usados, situación que es ampliamente aceptada para esta parasitosis ${ }^{1-3}$.

El uso de ivermectina resultó satisfactorio en dos de los tres miembros infectados de la familia En la hermana del caso índice, quien al cabo de un año presentó serología positiva con EPSD negativo, al ser interrogada refirió que no ingirió el medicamento de la manera indicada. El EPSD de esta niña probablemente sea falsamente negativo. Por el contrario, en la madre y caso índice se negativizó la serología y el EPSD con el tratamiento bien realizado. Es importante recalcar que en esta paciente fue muy acertado no haber usado corticoides para el tratamiento de su ARJ, pues podría haber desencadenado un síndrome de hiperinfección, como ya ha sido descrito².

No se han realizado estudios de prevalencia de esta parasitosis tanto en nacionales como en extranjeros que residen en Chile y esta infección no es considerada como una posible causa de síntomas abdominales. Además el escaso rendimiento del examen parasitológico de deposiciones, sugiere que la frecuencia de la strongyloidosis se encuentre subestimada.

En Chile, de acuerdo a lo observado en este estudio, el diagnóstico de las infecciones causadas por este parásito debiera ser dirigida a pacientes que presente eosinofília sanguínea moderada y que provengan de países reconocidamente endémicos utilizando métodos de laboratorio directos e indirectos como es ELISA, la que puede ser solicitada al Laboratorio de Referencia de Parasitología del Instituto de Salud Pública de Chile.

\section{RESUMEN}

Se presenta un brote familiar de strongyloidosis que afectó a inmigrantes peruanos que habían llegado a Chile en noviembre del año 2001. En marzo del 2002, se confirmó en el Laboratorio de Parasitología Básico-Clínico de la Facultad de Medicina de la Universidad de Chile que el caso índice presentaba infección por Strongyloides stercoralis. Correspondía a una menor de 11 años que estaba siendo estudiada en el Hospital Roberto del Río por artritis reumatoide juvenil. Además de esta patología la niña refería leves molestias abdominales, siendo derivada a nuestra unidad, donde se le efectuó un examen parasitológico seriado de deposiciones (EPSD), observándose abundantes larvas rabditoides de $S$. stercoralis, por lo cual se procedió a estudiar al grupo familiar integrado por los padres y una hermana. A todos ellos se les efectuó EPSD e inmunodiagnóstico mediante ELISA para detectar anticuerpos anti S.stercoralis. Resultaron positivos para ambos exámenes la madre y las dos hijas. El padre fue negativo. Se decidió tratar con ivermectina y controlar los resultados del tratamiento antiparasitario al grupo familiar al cabo de un año. Después de ese periodo permanecía positiva serológicamente, solamente la hermana del caso índice debido a que no ingirió los medicamentos de la manera indicada.

\section{REFERENCIAS}

1.- MERCADO R, JERCIC I, TORRES P et al. Inmunodiagnóstico de las infecciones por Strongyloides stercoralis en Chile utilizando la prueba de ELISA. Rev Méd Chile 2002; 130: 1358-64.

2.- AFZAL A SIDDIQUI, STEVEN L, BERK. Diagnosis of Strongyloides stercoralis Infection. Clin Infect Dis 2001; 33: 1040-7.

3.- DREYER G, FERNÁNDEZ-SILVA E, ALVES S et al. Patterns of detection of Strongyloides stercoralis in stool specimens: implications for diagnosis and clinical trials. J Clin Microbiol 1996; 34: 2569-71.

4.- ODDO D, DUARTE I. Síndrome de mala absorción por Strongyloides stercoralis. Caso de autopsia. Rev Méd Chile 1983; 111: 443-6.

5.- CORNEJO J, ARIAS B, SUBIABRE V et al. Estudio epidemiológico de protozoosis y helmintiasis intestinales en 490 pacientes crónicos del Hospital Psiquiátrico de Putaendo, V región, Chile. Bol Chil Parasitol 1985; 40: 91-3.

6.- JERCIC M I, MERCADO R, TORRES P, ALCAYAGA S. Confirmación de casos de strongyloidiasis humana en el Hospital Psiquiátrico «El Peral», Santiago, 2000. III Simposio Internacional de Parasitología, Santiago, Chile. 